\title{
Knowledge Management in Education
}

Jane Andersen

Open University, The IT University of Copenhagen, Glentevej 67, DK-2400 Copenhagen NV, Denmark

jane@it-c.dk

Key words: Knowledge Management, Catalyst for Adaptation, Distance Learning, Social Issues

Abstract: When the IT University of Copenhagen started in 1999 there was a manager but there were no students or teachers. In 2002 there are 1200 students and 150 teachers and these numbers will increase. Each teacher is appointed because of his or her outstanding IT knowledge, and he or she chooses the detailed IT content of his or her course. Students, as soon as they register, are given emails and logons to the Intranet, as email and Intranet are two of their main sources of information during their period of study. In terms of integration of IT in teaching the IT University of Copenhagen is similar to most other educational institutions. The knowledge is mainly managed individually by each teacher tacitly. This paper focuses on the main challenges to successful integration: conditions for generating knowledge on IT integration, knowledge management, management, traditions, social relations and net-based education.

\section{INTRODUCTION}

This paper is about knowledge management - generation, collection, organisation, dissemination, and usage of knowledge - and the successes, challenges and problems faced when developing and practising knowledge management in education. In my opinion the main aim of knowledge management is the usage of the knowledge.

The following reflections are based on the knowledge area 'IT in

The original version of this chapter was revised: The copyright line was incorrect. This has been corrected. The Erratum to this chapter is available at DOI: 10.1007/978-0-387-35663-1_34 
Education' with which I have been intensely involved. 'IT in Education' knowledge can typically be categorised at three levels:

- IT in teaching and learning at course level.

- IT strategies at school or institutional level.

- IT at the national level.

\section{PERSONAL RELIABILITY}

One of the biggest problems is the enormous volume of knowledge about IT in Education, which is not optimally used.

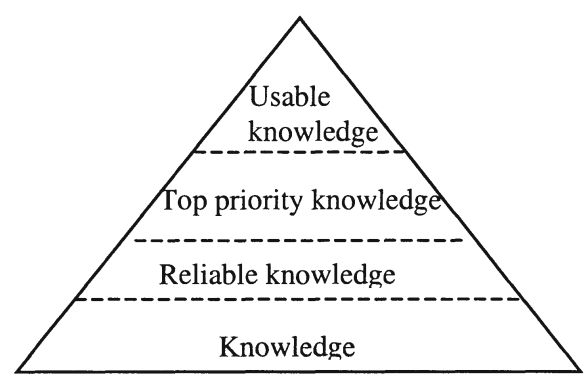

Figure 1. The personal reliability triangle of knowledge management

Postulate 1: I maintain that knowledge is only usable if it is firstly reliable, secondly given priority and finally made usable for the specific user or groups of users (Figure 1). In the education sector important groups of users are the teachers who need knowledge about teaching and learning, the managers who need knowledge at the strategic level and IT project managers and IT responsible staff who need knowledge about teaching and learning as well as knowledge at the strategic level.

Postulate 2: I further maintain that IT can be used for making knowledge usable but human interactions are important and necessary as well.

I will illustrate the importance of the personal reliability triangle through two examples I have experienced. The first example concerns knowledge management at the former CTU, The Danish National Centre of Technology Supported Learning, now known as Learning Lab Denmark. The other example is from my development post at the Open University Department based at the IT University of Copenhagen. 


\section{CTU}

The aims of CTU were to subsidise and support projects aimed at improving educational quality through the adoption of new technologies and to be a national knowledge centre on IT in education.

The main idea underlying the knowledge centre of CTU was that the production of knowledge was effected by the projects. They were paid to produce, structure and report results to CTU. Many Danish educational institutions received experiences with IT and CTU got very detailed knowledge on IT and institutional adaptation. CTU received the knowledge in a printed report and on disk - and we also talked with staff involved in most projects many times during the project period.

The primary way of organising the knowledge was the presentation of project reports on the web. From the projects we also extracted, restructured and concentrated the knowledge and we added services such as a copyright service for usage of electronic educational material. CTU never published a whole project report but extracted knowledge for printed articles and books.

For internal use all information on projects was kept both on paper and electronically. There were three primary ways of disseminating the knowledge: printed, web-based and 'mouth to mouth'.

\subsection{Types of knowledge - where were the successes?}

We experienced different degrees of success with the different types of knowledge. In respect to reliable knowledge the project groups did their work and returned their knowledge as reports, which went to the web. Some interested people, especially researchers and IT project managers, found these reports and printed them free of charge.

\subsection{Problems and challenges}

Following interviews with selected project groups and analysis of the project reports specific knowledge was assigned priority by the knowledge centre of CTU. This top priority knowledge was then printed and sold as 'CTU News', or included in books or conferences of anthologies.

Usable knowledge was created by further structuring and concentrating the knowledge and presenting it at thematic conferences, in instructional 'cook books' and as dedicated web services. These ready to use offers of knowledge were avidly requested and sold to many real users who were only interested in the knowledge when it was customised for them. 
Unfortunately, not everybody who could potentially gain knowledge by reading and using the resources knew about the books and web-services. This is a challenge for the owners of knowledge as well as the potential users.

\section{IT-C}

My reflections on the development of net-based education at The IT University of Copenhagen (IT-C) show an example of a development process based on mainly social and ethical decisions.

As head of development at The Open University Department at the three years old IT University my responsibilities are both the strategic implementation at university level and the design of the frameworks for teaching and learning.

At the teaching level one of the biggest challenge is that most teachers are not searching for knowledge on teaching at all (Lorentsen 2000). The teachers are researchers - although they are not researching in education and outstanding IT experts from industry. Course assessments show that most students are very satisfied with most of the courses.

\subsection{Phase 1}

The Open University Department started in 2001 with three net-based courses. The three teachers involved in the delivery of net-based education had their own experiences from two years of net-based teaching at other universities. I have never practised net-based teaching, but I have studied and worked with distance education for years in Denmark and internationally (Paulsen 2001).

How could we exchange knowledge? Were the teacher's experiences more or less important than the knowledge I had picked up over the years? I decided on a knowledge exchange model where we talked about important aspects of net-based education at face to face meetings. Knowledge transfer was always based on debate such as "My experiences with ... are ...", and "Experiences from many projects report very good experiences with ... Should we try to invoke this in our concept too?" I categorise this as knowledge exchange by negotiation.

For me the social aspects of the development process were very important. Looking at the speed of development it was not the quickest and most efficient strategy to choose but for developing a "social climate" in our group of teachers I am certain it was the best way. 


\subsection{Phase 2}

The four new teachers joining us in 2002 had no experience of net-based teaching. Each new teacher was introduced individually because I needed to know their teaching background, their experiences with net-based teaching and their feelings about the new way of teaching. Were they expecting netbased teaching to be a challenging friend or a time-consuming enemy?

The knowledge management situation has changed, both because of the new teachers and because of the experiences gathered at the IT-university during 2001. I wrote an eight-page introduction (directives as well as advice and ideas) to net-based education at the university where I collected both experiences from university teaching and my own knowledge in the area. This was the first time that I was able to introduce and implement a more substantial part of my knowledge.

The written introduction was given to all teachers for discussion and stimulation of the exchange of ideas between the 'new' and the 'old' teachers. However, only the new teachers showed up for the meeting I set up for discussion!

I categorise this as knowledge exchange based on the apprenticeship principle.

\subsection{Phase 3}

At the conclusion of the spring term 2002 we asked the 200 students to evaluate the courses. Their opinions will be very important. It will be my responsibility to make fair conclusions, praise the successes and prepare solutions for adjustments of problematic areas to push the further development process in co-operation with the teachers.

I am sure that some knowledge management can be done by writing a common paper and meeting in groups - but I am also sure that there need to be face to face meetings and talks between each of the teachers and myself.

A further step in knowledge management will be the provision of webbased information for potential students about the qualities of our net-based education. This pre-course preparation and support of students will give them more substantial expectations which everybody involved in net-based education throughout the IT University will be responsible for implementing.

\subsection{Characteristics of the knowledge management}

Generation and collection of knowledge was carried out by the teachers and myself through years of working experiences before the start of the 
university. To a great extent the knowledge was organised as tacit knowledge in our heads in phase one. This organisation of knowledge changed during phase two where I evaluated the experiences and made priorities before making dedicated directives and catalogues of ideas about net-based education for teachers as well as for students. The knowledge is disseminated through talk and print as well as by email and Internet websites. Usage of knowledge could be seen during the term where some students used the "good old" question and answer method before searching through the directives while other students did the opposite.

\section{IT IN KNOWLEDGE MANAGEMENT}

What can IT do for knowledge management in the education sector? IT cannot make knowledge reliable or give priority to knowledge, but IT can be used for making knowledge usable. As usable knowledge is the most important form of knowledge IT is very important for knowledge management in the education sector.

An outstanding example of usable knowledge is the Danish Poseidon Project (Poseidon 2002), which has a web-based toolbox for development of IT strategies at educational institutions. Through pre-prepared checklists and questionnaires the educational institution completes a statement of current practices and is helped to articulate their vision, aim and plan of operation of ICT integration. The toolbox has been tested and used by several hundred Danish educational institutions from primary schools to universities. It has been translated into English, French, Portuguese and Dutch as a part of the European Network of Innovative Schools (ENIS 2002) and is freely available on the web.

\subsection{Challenges and real problems}

Working with IT in education for many years I have identified the following challenges and problems which make it complicated to disseminate knowledge and secure usage of knowledge.

Usable knowledge is individually identified:

- You can only expect usage of knowledge if the user thinks that the knowledge is important.

- Teachers, IT project managers and managers expect different kinds of usable knowledge.

- Researchers focus on reliable knowledge, developers on high priority knowledge and users on usable knowledge. 
Most knowledge about IT in education is never made usable:

- Many projects have produced reliable knowledge on IT in education, but the investment in the process of making reliable knowledge usable is too small.

The characteristics of usable knowledge need more investigation.I am finding these problems formidable and my suggestion is that all universities and other educational institutions, together with regional and national knowledge centres, should set up strategies for all aspects of knowledge management.

\section{EDUINFOLEARNKNOW}

The future knowledge management and learning situation will be existentially affected by the ongoing mix of education, information, learning and knowledge management into a kind of EduInfoLearnKnow (Figure 2).

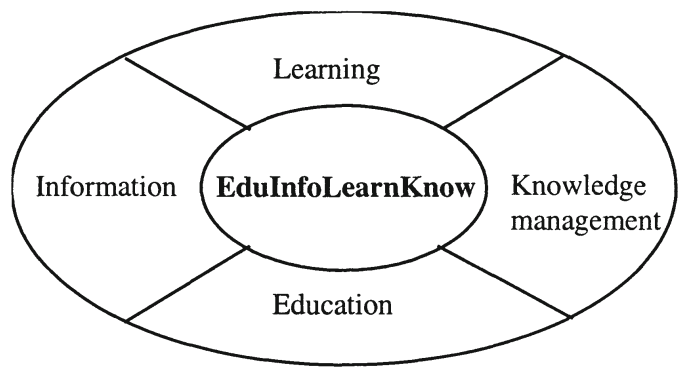

Figure 2. EduInfoLearnKnow

A tendency at the moment is to label everything in this area e-learning, which definitely will change e-learning and the whole principle of learning! The last time I met with industry representatives they told me that it makes no difference how and from where they get knowledge - as long as they are gaining something.

If we don't react I think e-learning will very shortly end up as einformation. That is not the result of IT in education I am looking forward to! 


\section{REFERENCES}

Lorentsen, A. (2000) Aspekter af teknologistoettet fjernundervisning paa universitetsniveau. University of Aalborg.

[http://www.sprog.auc.dk/persons/]

Paulsen, M. F. (2001) Netbasert Utdanning. Gyldendal. Denmark. (Danish introduction by Andersen, $\mathrm{J}$ and Andresen, B. B.)

The IT University of Copenhagen (2002).

[www.it-c.dk]

Poseidon (2002). The Danish Poseidon Project.

[www.poseidon.uvm.dk]

CTU (2002) The Danish National Centre of Technology Supported Learning.

[www.ctu.dk]

LLD (2002) Learning Lab Denmark.

[www.lld.dk]

ENIS (2002) European Network of Innovative Schools.

[http://www.enis.eun.org/Toolbox/overblik.htm] 